\title{
Design of CPW-Fed Small Multi-Band Antenna by Using Band Rejection Semicircle Slot
}

\author{
Xiao Li $\cdot$ Seungwoo Lee $\cdot \mathrm{Nam} \mathrm{Kim} \cdot$ Chul-Ho Kim
}

\begin{abstract}
This paper presents a CPW-fed antenna with three slots. The proposed antenna can operate at $1.9 \sim 2.1 \mathrm{GHz}$ and $2.9 \sim 3.3 \mathrm{GHz}$ which are generated by the two rectangular slots, and $4.5 \sim 11.6 \mathrm{GHz}$ which is generated by the main patch. The semicircle-slot is used as a band-notched filter to stop at a desired band $(5.150 \sim 5.825 \mathrm{GHz})$ limited by IEEE 802.11a or HIPERLAN/2 applications. The currents concentrate around corresponding slots at the desired band. The proposed antenna is very small in size, with overall dimensions of $27 \times 32 \times 1 \mathrm{~mm}^{3}$ etched onto an FR4-printed circuit board (PCB).
\end{abstract}

Key words: CPW-Fed, Band-Notched, UWB, WLAN.

\section{Introduction}

Antenna design is facing a big challenge for wireless mobile devices where multiple communication services are integrated into the same piece of hardware. It is necessary to design multi-band antennas to meet the requirements of multiple services. Ultra-wideband (UWB) technology has attracted attraction due to its advantages, such as high date rate, very low power consumption, and suitability for medium-range indoor communication [1]. Wireless local area network (WLAN) and Bluetooth technology have similar functions which can be used for personal computers, mobile devices, home networks, etc.

UWB transmitters should not cause any electromagnetic interference to nearby communication systems. However, the UWB frequency range includes IEEE 802.11a wireless or HIPERLAN/2 local area networks. Therefore the UWB antenna should be designed with a notched characteristic at interference band. Many methods for a band notch have been studied, where various slot types (V-shaped slots, U-shaped slots, H-shaped slots, T-shaped stubs and inverted-L shaped slits) are inserted on the main patch [2] [4].

In this paper, we propose a CPW-fed antenna with three different slots in which two $\cap$-shaped slots are used to generate the center frequency at $2.0 \mathrm{GHz}$ and 3.1 GHz, while the semicircle slot is used to the stop band from 5.1 to $5.9 \mathrm{GHz}$. The operations are achieved when the length of each slot is one-half the wavelength of the desired band.

\section{II . Antenna Design and Results}

\section{2-1 The Structure of Proposed Antenna}

The proposed antenna shown in Fig. 1 is printed onto the side of a piece of FR4 PCB $\left(27 \times 32 \mathrm{~mm}^{2}\right.$, thickness of $1 \mathrm{~mm}$ ) with a relative dielectric constant of 4.4 , and a loss tangent of 0.02 . The width of feed line $W_{f}$ is fixed at $3 \mathrm{~mm}$ to achieve a $50-\Omega$ characteristic impedance. Parameters of the proposed antenna are shown in Table 1. All these parameters have already been optimized.

\section{2-2 Different Function of Slots}

Fig. 2(a) shows that the slot is used to excite desirable resonance. When the length of the slot is onehalf the wavelength of the desired band, the resonance

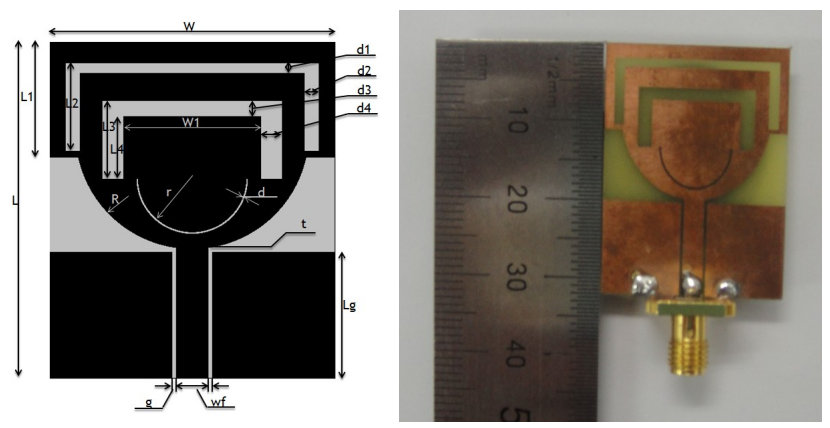

Fig. 1. The structure of proposed antenna.

Manuscript received April 14, 2011 ; revised August 26, 2011. (ID No. 20110414-017J)

Information and Communication Engineering, Chungbuk National University, Chungbuk, Korea.

Corresponding Author : Nam Kim (e-mail : namkim@chungbuk.ac.kr) 
Table 1. Parameters of the proposed antenna.

\begin{tabular}{|c|c|c|c|c|c|}
\hline Parameters & $\begin{array}{c}\text { Unit } \\
{[\mathrm{mm}]}\end{array}$ & Parameters & $\begin{array}{c}\text { Unit } \\
{[\mathrm{mm}]}\end{array}$ & Parameters & $\begin{array}{c}\text { Unit } \\
{[\mathrm{mm}]}\end{array}$ \\
\hline$W$ & 27 & $L_{2}$ & 8.4 & $d_{2}$ & 1.4 \\
\hline$L$ & 32 & $L_{3}$ & 7.5 & $d_{3}$ & 1.5 \\
\hline Thickness & 1 & $L_{4}$ & 6 & $d_{4}$ & 2 \\
\hline$w_{1}$ & 14.6 & $d$ & 0.3 & $w_{f}$ & 3 \\
\hline$L_{1}$ & 11 & $d_{1}$ & 1 & $l_{g}$ & 12 \\
\hline$t$ & 0.2 & $r$ & 5.1 & $R$ & 11 \\
\hline
\end{tabular}
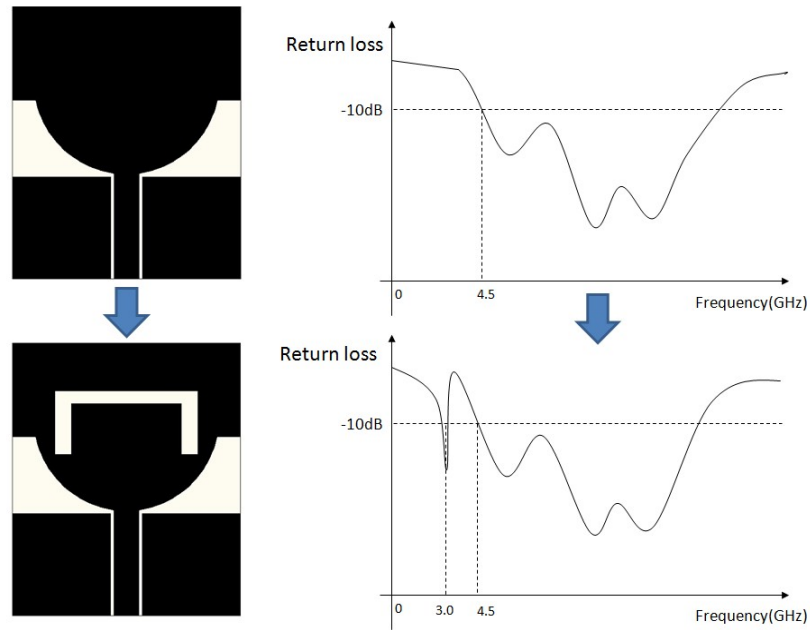

(a) Slot excites resonance
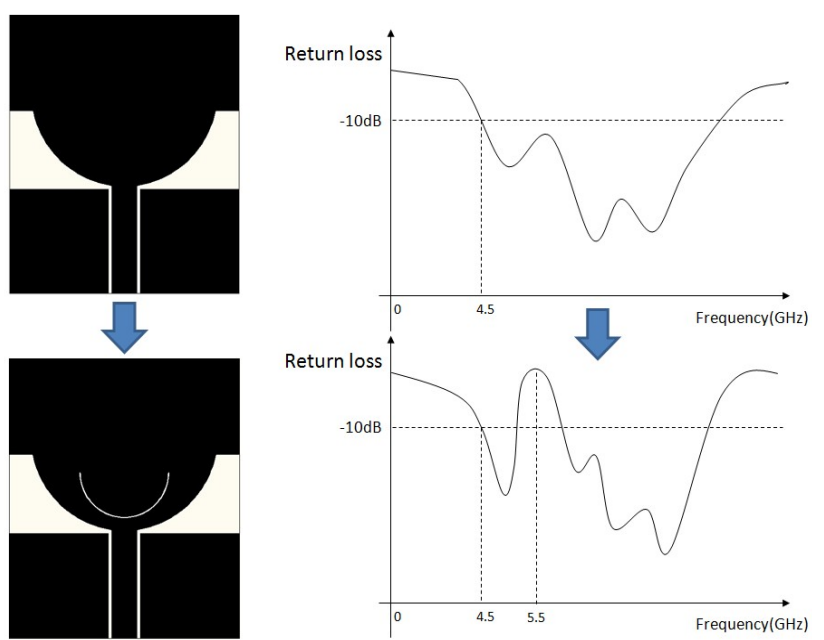

(b) Slot used as band-notched filter

Fig. 2. Slots used as different function.

occurs. With this principle, we use a similar slot to realize the frequency band expansion.

In Fig. 2(b), the slot is used to stop a desired band as the band-notched filter. Although many methods for a band notch have been studied, considering the coupling effect between slots, we use a semicircle-shaped slot.

\section{2-3 Parameter Optimization}

For a suitable observation of the influence of different parameters on these three slots, only one parameter is investigated at a time. The current distribution demonstrates that the resonant frequency will be changed by tuning the length of each slot. The effect of two $\cap$ shaped slots and the semicircular slot is shown in Fig. 3.

In Fig. 3(a), the $L_{2}$, one parameter of upper $\cap$-shaped slot, is changed while the other parameters remain fixed. The lower resonant frequency at $2 \mathrm{GHz}$ is observed when $L_{2}$ increases. This demonstrates the resonant frequency moving to a lower band, and the desired band is attained when the size is close to $7 \mathrm{~mm}$.

In Fig. 3(b), for the same effects of parameter $L_{2}$, the resonant frequency moves to a higher band at $3.1 \mathrm{GHz}$ when $L_{3}$, one parameter of middle $\cap$-shaped slot, decreases. The determined size is $6 \mathrm{~mm}$.

Fig. 3(c) shows that the resonant frequency moves to a higher band when the parameter $d$ (the width of the semicircular slot) increases. When $d$ is fixed at $0.3 \mathrm{~mm}$, it will satisfy the expected band.

\section{2-4 Current Distribution}

Fig. 4 shows the current distribution for each slot at 2.1 GHz, 3.1 GHz, and 5.5 GHz. The current distribution at $2.1 \mathrm{GHz}$ is mainly distributed in the upper slot (Fig. 4(a)). This implies that the upper slot is the major radiation element for the lower band. For the distribution at $3.1 \mathrm{GHz}$, currents concentrate mainly around the middle slot (Fig. 4(b)); and at $5.5 \mathrm{GHz}$, most currents are distributed in the semicircular slot (Fig. 4(c)). This demonstrates that the length of the semicircular slot affects the notch-band frequency. It seems that the most radiating parts are near the slots and steps. The feeding line and the boundary of the main patch also affect the radiation.

\section{2-5 Simulation and Measurement Results}

The proposed antenna exhibits a return loss of less than $-10 \mathrm{~dB}$, as shown in Fig. 5. The measured frequency bands are $1.9 \sim 2.1 \mathrm{GHz}, 2.9 \sim 3.3 \mathrm{GHz}, 4.5 \sim 5.5$ $\mathrm{GHz}$, and $6.5 \sim 11.6 \mathrm{GHz}$ under $-10 \mathrm{~dB}$. By inserting two $\cap$ - shaped slots on the patch, additional resonances are excited at $1.9 \sim 2.1 \mathrm{GHz}$ and $2.9 \sim 3.3 \mathrm{GHz}$ because of its effectiveness. But due to the coupling effect between the two $\cap$-shaped slots, the measured result at the lower band has a small deviation when compared to the simulation result. The modified semicircular slot on the patch is adopted to generate notched bands with the central frequency of $5.5 \mathrm{GHz}$, as well as the coupling effect between the middle $\cap$-shaped slot and the semicircular slot. 

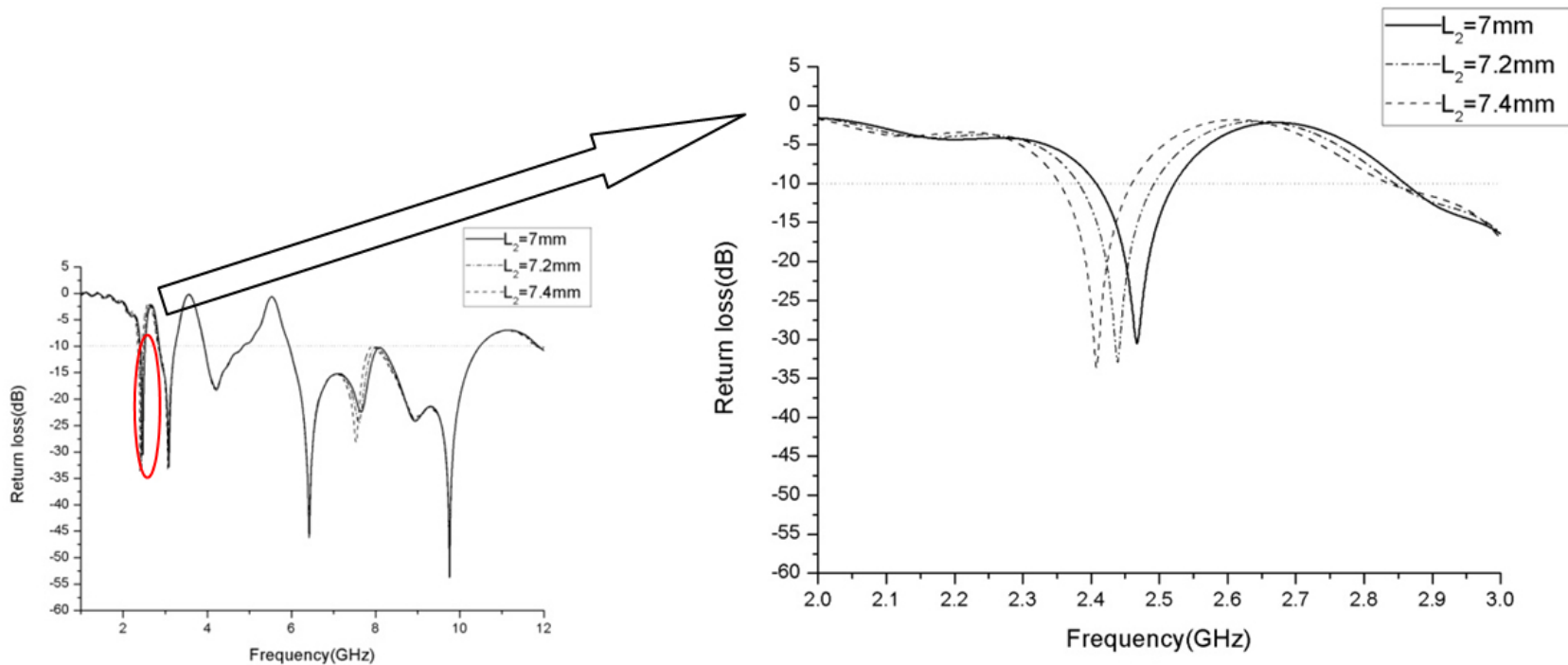

(a) Return loss variation by parameter $L_{2}$

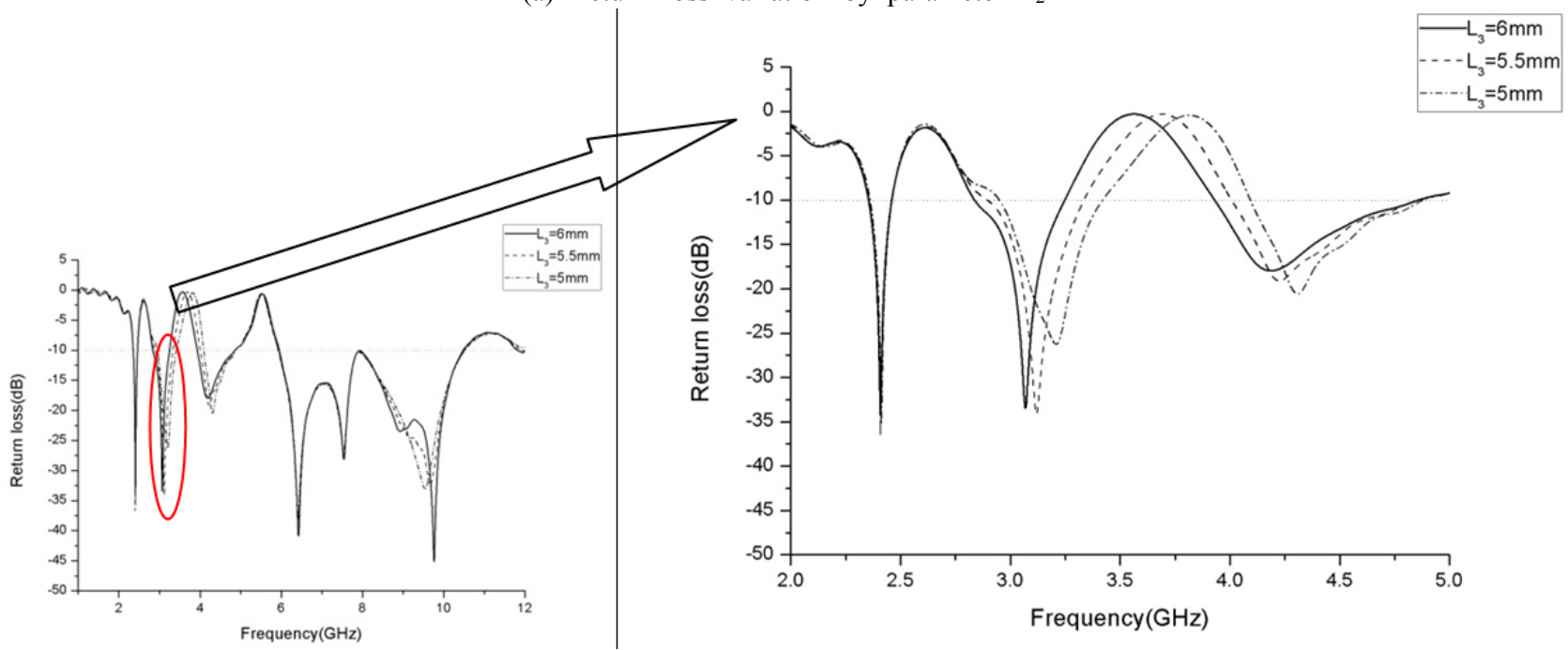

(b) Return loss variation by parameter $L_{3}$

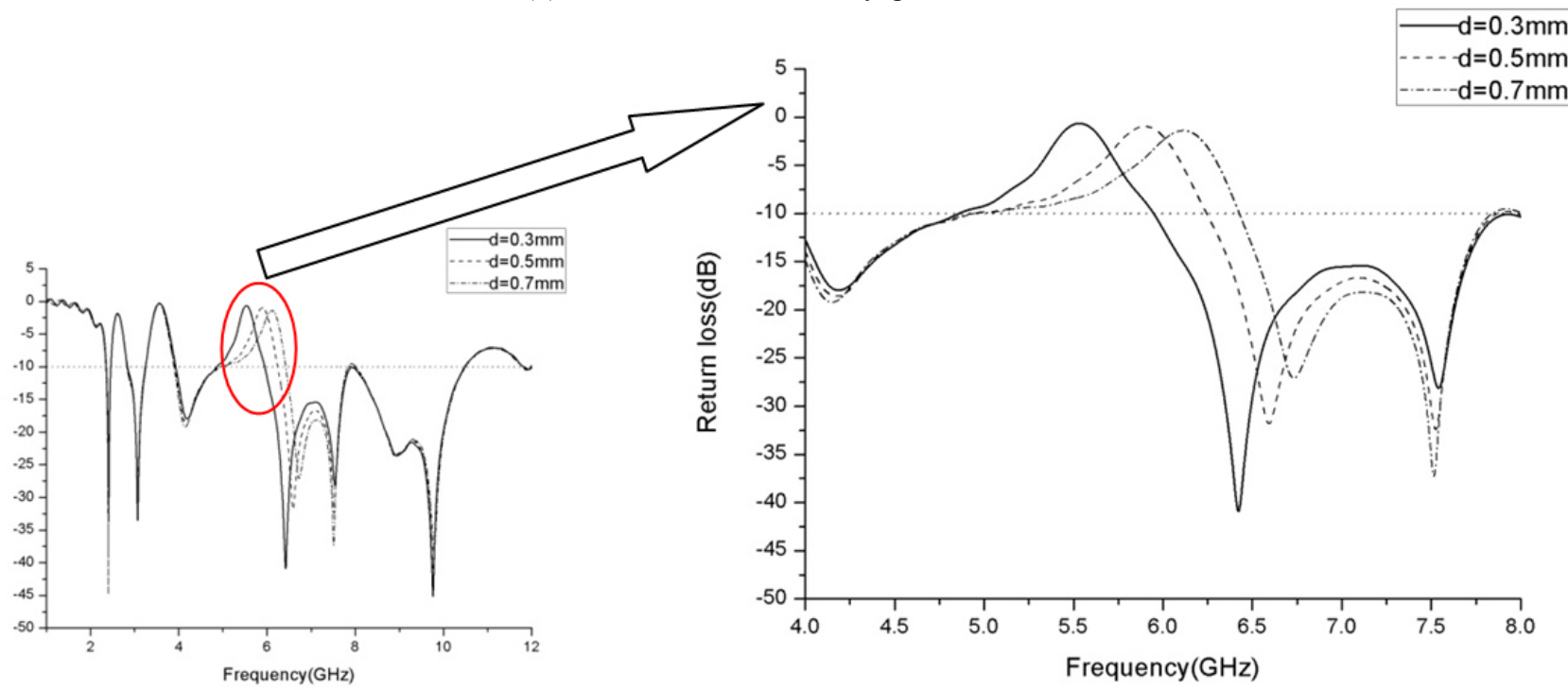

(c) Return loss variation by parameter $d$

Fig. 3. Parameter optimization. 


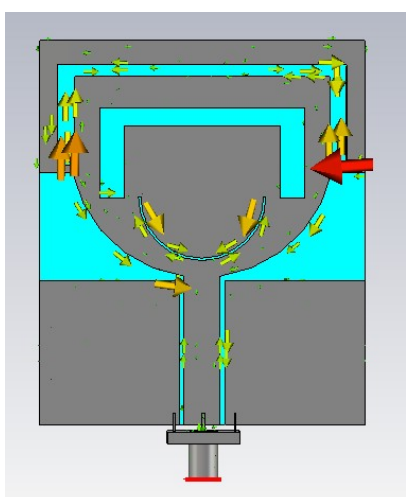

(a) Currents flow at $2.1 \mathrm{GHz}$

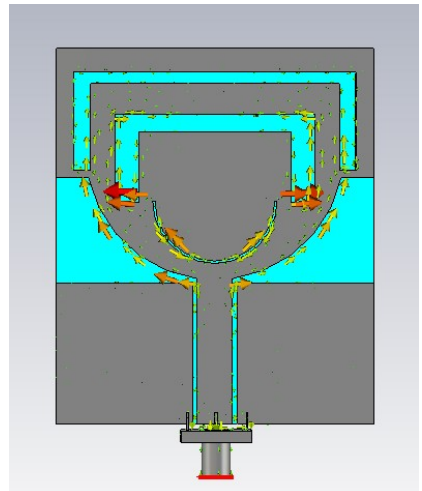

(b) Currents flow at $3.1 \mathrm{GHz}$

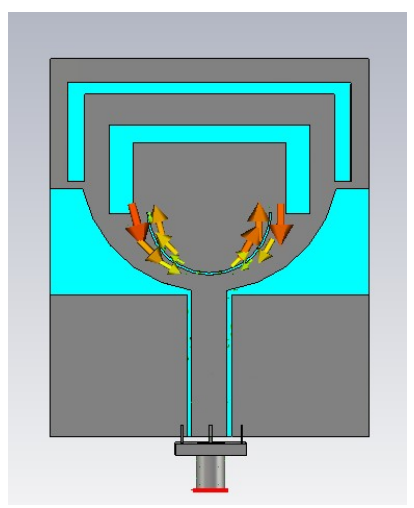

(c) Currents flow at $5.5 \mathrm{GHz}$

Fig. 4. The current distribution of each slot.

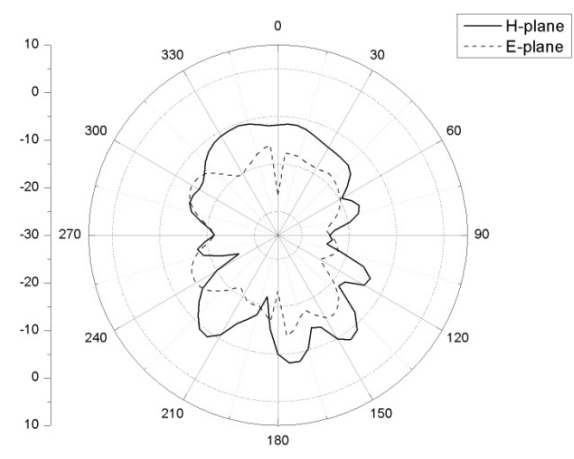

(a) $2.45 \mathrm{GHz}$

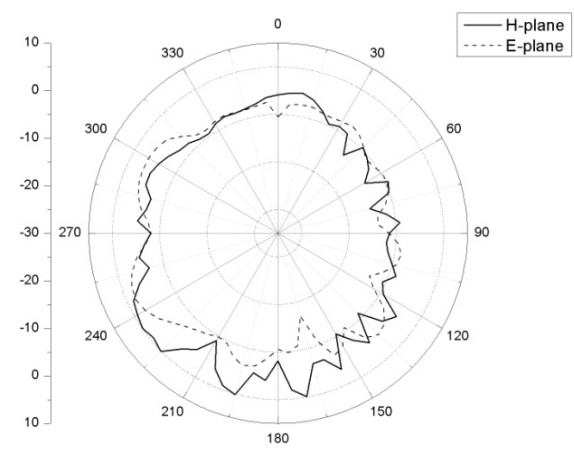

(c) $4.28 \mathrm{GHz}$

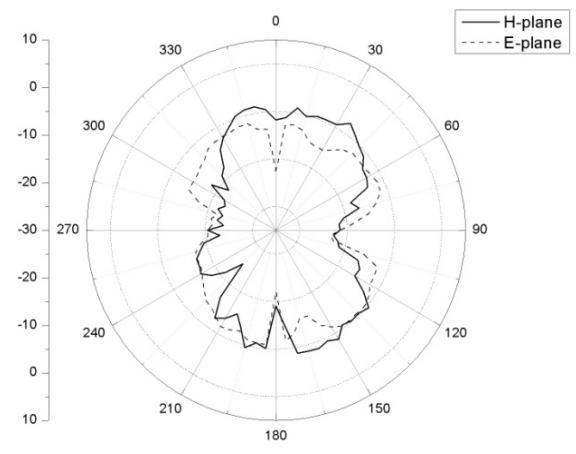

(e) $7.60 \mathrm{GHz}$

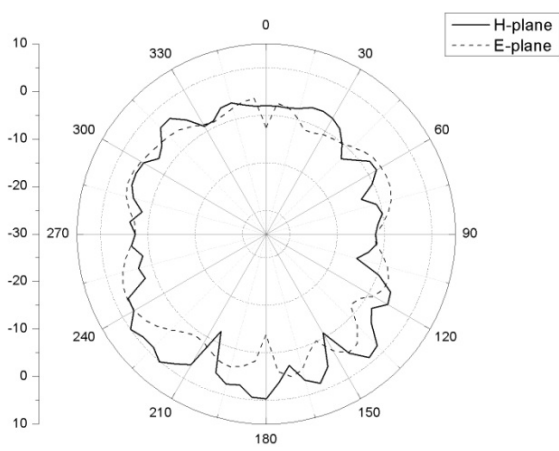

(b) $3.14 \mathrm{GHz}$

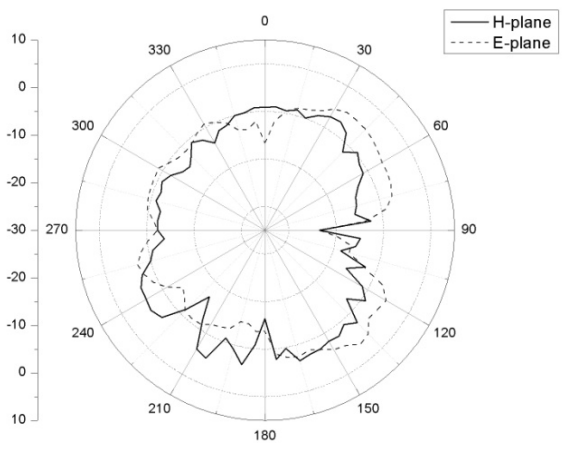

(d) $6.50 \mathrm{GHz}$

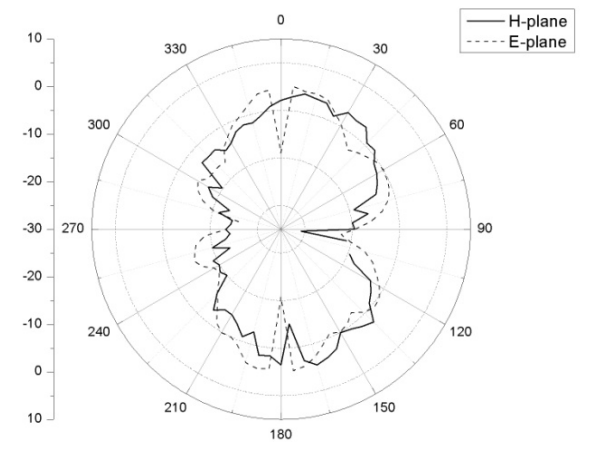

(f) $10.0 \mathrm{GHz}$

Fig. 6. The measured radiation patterns at each resonant frequency. 


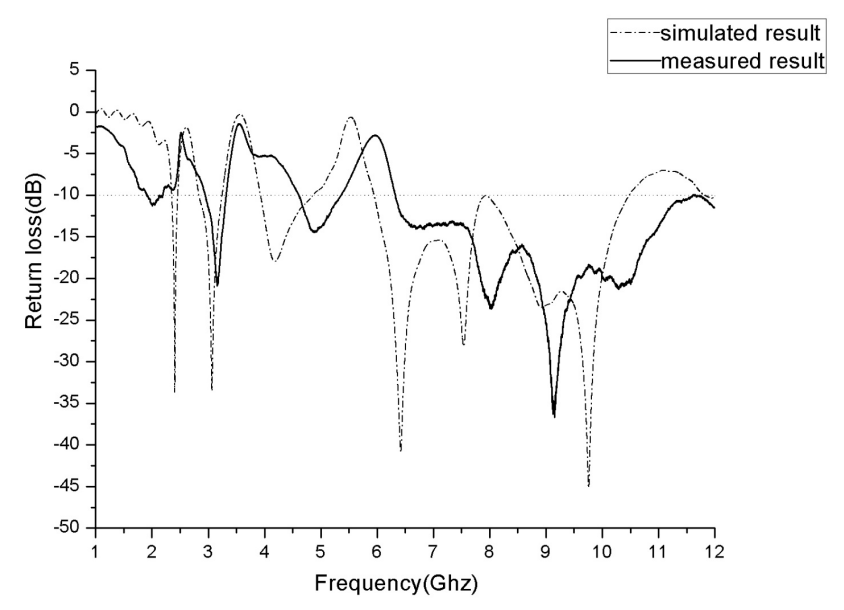

Fig. 5. Comparison of the simulated result with the measured result of the return loss.

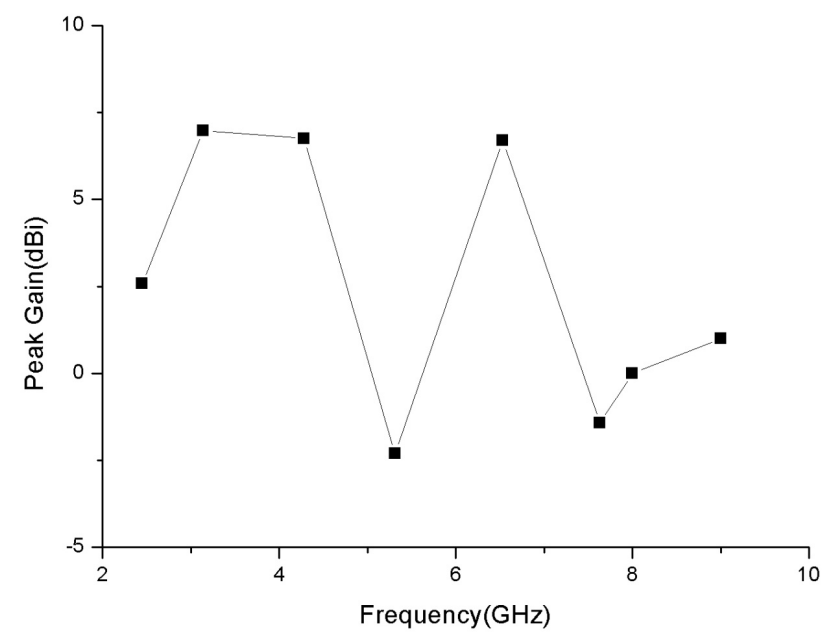

Fig. 7. The measured peak gain of the proposed antenna.

\section{2-6 Radiation Pattern and Gain}

The measured far-field radiation patterns of the proposed antenna at $2.45 \mathrm{GHz}, 3.14 \mathrm{GHz}, 4.28 \mathrm{GHz}, 6.5$ $\mathrm{GHz}, 7.6 \mathrm{GHz}$, and $10.0 \mathrm{GHz}$ for E-plane and H-plane are shown in Fig. 6, and the measured peak gain of the proposed antenna is shown in Fig. 7. As the figures show, the radiation patterns for the H-plane are omni-directional in shape, and the patterns in the E-plane are close to bidirectional, whereby, these are the monopole antenna characteristics. This indicates that a large and uniform coverage for a UWB system operation can be attained.

The measured antenna gain versus frequency is plotted in Fig. 7. At passband, the antenna gain varies stably from 2.92 to $6.49 \mathrm{dBi}$. But the lower performance for the gain has dropped to about $-2 \mathrm{dBi}$ over the stopband frequency of $5.3 \mathrm{GHz}$. In addition, when frequency goes beyond $7 \mathrm{GHz}$, the peak gain is very weak.

\section{Conclusion}

In this paper, we proposed a CPW-fed small size antenna with three optimized slots in order to achieve excellent band-notched characteristics and excite two resonances. This antenna has an excellent performance of reflection coefficient from $1.9 \sim 2.1 \mathrm{GHz}, 2.9 \sim 3.3 \mathrm{GHz}$, $4.5 \sim 5.5 \mathrm{GHz}$, and $6.5 \sim 11.6 \mathrm{GHz}$. The radiation patterns are omni-directional shapes with high gains. Accordingly, the proposed antenna is expected to be a good candidate in various UWB systems.

This work was supported by the grant of the Korean Ministry of Education, Science and Technology (The Regional Core Research Program / Chungbuk BIT Research-Oriented University Consortium)

\section{References}

[1] C. Kim, J. Jang, Y. Jung, H. Lee, J. Kim, S. Park, and $\mathrm{M}$ S. Lee, "Design of a frequency notched UWB antenna using a slot-type SRR," International Journal of Electronics \& Communication, vol. 63, no. 12, pp. 1087-1093, Dec. 2009.

[2] H. K. Lee, J. K. Park, and J. N. Lee, "Design of a planar half-circle-shaped UWB notch antenna," $M i$ crowave and Optical Technology Letters, vol. 47, no. 1, pp. 9-11, Oct. 2005.

[3] T. G. Ma, S. K. Jeng, "Planar miniature taperedslot-fed annular slot antennas for ultra-wideband radios," IEEE Trans. Antennas Propagation, vol. 53, no. 3, pp. 1194-1202, Mar. 2005.

[4] Y. Zhang, W. Hong, C. Yu, Z. Q. Kuai, Y. D. Don, and J. Y. Zhou, "Planar ultra-wideband antennas with multiple notched bands based on etched slots on the patch and/or split ring resonators on the feed line," IEEE Trans. Antennas Propagation, vol. 56, no. 9, pp. 3063-3068, Sep. 2008.

[5] Z. N. Chen, M. J. Ammann, X. M. Qing, X. H. Wu, T. S. P. See, and A. Cai, "Planar antennas," IEEE Microwave Magazine, vol. 7, no. 6, pp. 63-73, Dec. 2006.

[6] Z. Q. Wang, W. Hong, Z. Q. Kuai, C. Yu, Y. Zhang, and Y. D. Dong, "Compact ultra-wideband antennas with multiple notches," Proceeding of ICMMT Conference, pp. 266-269, 2008.

[7] L. Peng, C. L. Ruan, Y. L. Chen, and G. M. Zhang, "A novel band-notched elliptical ring monopole antenna with a coplanar parasitic elliptical patch for 
UWB applications," Journal of Electromagnetic Waves and Applications, vol. 22, no. 4, pp. 517-528, Apr. 2008.

[8] K. H. Kim, S. O. Park, "Design of the band-rejected UWB antenna with the ring shaped parasitic patch," Microwave and Optical Technology Letters, vol. 48, no. 7, pp. 1310-1313, Apr. 2006.

[9] K. H. Kim, Y. J. Cho, S. H. Hwang, and S. O. Park, "Design of a band-rejected UWB planar monopole antenna with two parasitic patches," Electronics Letters, vol. 41, no. 14, pp. 957-960, 2005.

[10] H. G. Schantz, G. Wolenec, and E. M. Myszka, "Fre-
Xiao Li

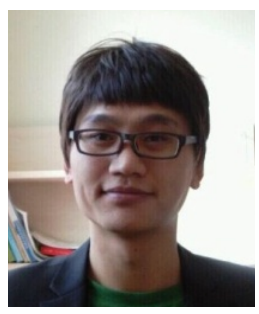

received a B.S. degree in School of Information Science \& Engineering from Harbin Institute of Technology at Weihai in China. He worked at Harbin Institute of Technology from 2004 to 2008 . He is currently working on a master's degree at Chungbuk National University, Korea. His research interests include the design of UWB antennas and Radio Frequency Identification. quency notched UWB antennas," Proceeding of IEEE Ultra Wideband System Technology Conference, pp. 214-218, 2003.

[11] Q. X. Chu, Y. Y. Yang, "A compact ultra-wideband antenna with $3.4 / 5.5 \mathrm{GHz}$ dual band-notched characteristics," IEEE Trans. Antennas Propagation, vol. 56, no. 12, pp. 3637-3644, Dec. 2008.

[12] W. S. Lee, D. Z. Kim, K. J. Kim, and J. W. Yu, "Wideband planar monopole antennas with dual bandnotched characteristics," IEEE Trans. Microwave Theory Technology, vol. 54, no. 6, pp. 2800-2806, Jun. 2006.

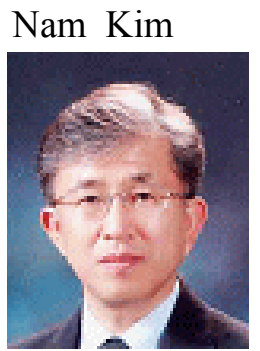

received the B.S., M.S. and Ph.D. degrees in the electronics engineering from Yonsei University, Seoul, Korea, in 1981, 1983, and 1988 respectively. $\mathrm{He}$ is a professor at Chungbuk National University in Korea from 1989 and a member of Research Institute for Computer and Information Communication. He served as a member of the BEMS Board, At Large, from 2006 to 2009. From 1996, he is a key member and now a chairman of the Committee on the EMF and human hazard in the KIEES, which Committee made the guideline for the EMF exposure and recommended it to the Korea government. His scientific interests are focused on the health effect of the EMF, RF dosimetry and SAR, the reduction and protection technology of the EMF hazards, and the guideline and standards on the EMF.
Seungwoo Lee

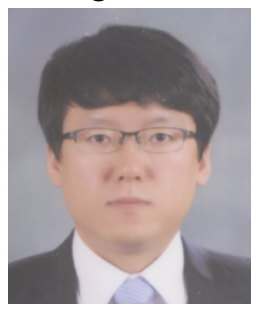

received a B.S. degree in electronics engineering from Chungbuk National University of Korea in 2003, and a M.S. degree in computer and communication engineering from Chungbuk National University, Korea, in 2006. He worked at Chungbuk National University of Korea from 2003 to 2006 . He is currently working on a Ph.D. at Chungbuk National University, Korea. His research interests include the antenna design and SAR analysis, the health effects of EMF, and the EMI/EMC research.

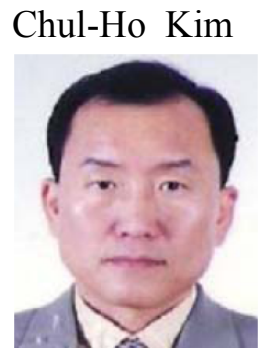

received a M.S. degree from Yonsei University, Seoul, Korea, in 2002. He is working at Kyoungjin ECT Engineering until now. His research interests include the antenna design, EMI/EMC, and the health effects of EMF. 